Article

\title{
The Role of Support Hydrophobicity in the Selective Hydrogenation of Enones and Unsaturated Sulfones over $\mathrm{Cu} / \mathrm{SiO}_{2}$ Catalysts
}

\author{
Denise Cavuoto ${ }^{1,2}$, Federica Zaccheria ${ }^{2, *}$, , Marcello Marelli ${ }^{3}\left(\mathbb{D}\right.$, Claudio Evangelisti $^{4} \mathbb{C}_{\text {, }}$ \\ Oreste Piccolo $^{5}$ (D) and Nicoletta Ravasio ${ }^{2}$ (D) \\ 1 Department of Chemistry, University of Milano, Via Golgi 19, I-20133 Milano, Italy; denise.cavuoto@unimi.it \\ 2 CNR SCITEC, Via C. Golgi 19, I-20133 Milano, Italy; nicoletta.ravasio@scitec.cnr.it \\ CNR SCITEC, Via G. Fantoli 16/15, I-20138 Milano, Italy; marcello.marelli@scitec.cnr.it \\ CNR ICCOM, Via G. Moruzzi 1, I-56124 Pisa, Italy; claudio.evangelisti@cnr.it \\ 5 SCSOP, via Bornò 5, I-23896 Sirtori (LC), Italy; contact@scsop.it \\ * Correspondence: federica.zaccheria@scitec.cnr.it; Tel.: +39-02-50314384
}

Received: 17 April 2020; Accepted: 5 May 2020; Published: 7 May 2020

check for updates

\begin{abstract}
The substitution of complex hydrides and Ni- and noble metal-based catalysts in the synthesis of pharma and fragrance products is a relevant topic in the green chemistry scenario. Here, we report that non-toxic, non-noble metal-based $\mathrm{Cu} / \mathrm{SiO}_{2}$ catalysts are effective and very selective in the hydrogenation of $\alpha, \beta$-unsaturated ketones, esters and sulfones under very mild conditions. Vanillyl acetone can be obtained in quantitative yield in $1 \mathrm{~h}$ at $90^{\circ} \mathrm{C}$ and $1 \mathrm{bar}$ of $\mathrm{H}_{2}$. High dispersion of the metallic phase and support wettability play a significant role in determining catalytic performance.
\end{abstract}

Keywords: Cu catalysts; unsaturated ketones; unsaturated sulfones; selective hydrogenation

\section{Introduction}

The selective hydrogenation of $\alpha, \beta$-unsaturated ketones represents an important transformation step in a series of synthetic routes due to the easy preparation of $\alpha, \beta$-enones via condensation [1] and the importance of the corresponding saturated ketones for pharmaceutical and flavor and fragrance $(F \& F)$ applications [2]. The synthesis of enones mainly relies on condensation reactions that allow one to obtain the $\alpha, \beta$-unsaturated products in high yield and under consolidated procedures. The following selective hydrogenation of the $C=C$ double bond, while leaving the $C=O$ group unaffected, gives the corresponding saturated ketones (Scheme 1).

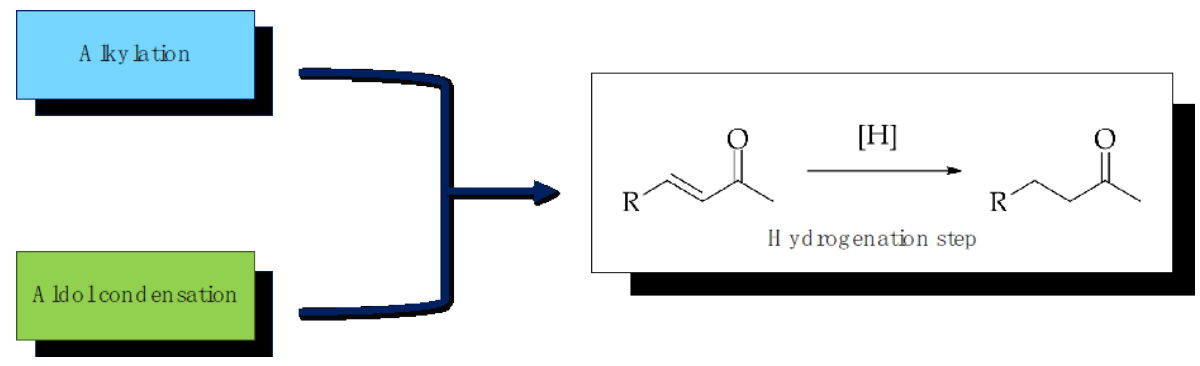

Scheme 1. Different strategies for the synthesis of enones and the following hydrogenation step.

This is the case of Nabumetone ${ }^{\circledR}$ [4-(6-methoxy-2-naphtalenyl)-2-butanone] (Scheme 2), a nonacidic broad-spectrum anti-inflammatory, analgesic and antipyretic. All the synthetic strategies employed 
entail the selective hydrogenation of the corresponding parent enone as the last preparation step [3-7]. In the open literature, it is reported to be efficiently hydrogenated under continuous-flow conditions by using $\mathrm{Ni} / \mathrm{Raney}$ or $\mathrm{Pd} / \mathrm{C}$ [8]. On the other hand, $\mathrm{Rh} / \gamma-\mathrm{Al}_{2} \mathrm{O}_{3}$ prepared by deposition of rhodium nanoparticles from mesitylene-solvated rhodium atoms stabilized by trioctylamine [9] or Pd-pyridine poly(L-lactide) macrocomplex [10] were effectively used in batch reaction conditions.<smiles>CCC(=O)CCc1ccc2cc(OC)ccc2c1</smiles>

Nabumetone $e^{\circledast}$<smiles>CC(=O)CCC1=C(C)CCCC1(C)C</smiles>

Dihydro- $\beta$-ionone<smiles>CCC(=O)CCc1ccc(O)cc1</smiles>

Raspberry ketone<smiles>O=C(CCc1ccccc1)c1ccccc1</smiles>

Dihydrochalcone<smiles>CCC(=O)CCc1ccc(O)c(OC)c1</smiles>

Vanillyl acetone.

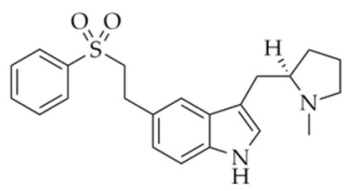

Eletriptan $^{\circledast}$

Scheme 2. Selectively hydrogenated products.

The synthesis of some food and flavor additives involves the same selective reduction as well. Raspberry ketone, 4-(4-hydroxyphenyl)-2-butanone and vanillyl acetone (zingerone), 4-(4-hydroxy3-methoxyphenyl)-butan-2-one are examples of this protocol [11] (Scheme 2). The former compound is a naturally occurring product which is found not only in raspberries but also in grapes, apples and peaches. Its fruity flavor and fragrance make it one of the most widespread additives in foods and cosmetics. Moreover, it has recently shown anti-insulin resistance and weight control activity [12]. The latter is one of the major components responsible for the ginger flavor after cooking. It has also been demonstrated that this compound has anti-diarrheal properties [13]. The high costs of these two natural extracted compounds led to the industrial use of the synthetic route, in which the last step is the selective double bond hydrogenation. This last step can be carried on for both substrates using $\mathrm{NiB}_{2}[14]$ or $\mathrm{Rh} / \mathrm{Al}_{2} \mathrm{O}_{3}$ [15] catalyst in presence of $\mathrm{H}_{2}$.

The selective hydrogenation of enones is also an important topic in terpene chemistry. $\beta$-ionone and the analogue dihydro- $\beta$-ionone (Scheme 2 ), for example, are naturally occurring molecules found in violet and rose essential oils, and they are widely used in the formulation of fragrances. Following a synthetic strategy, the latter can be obtained through the selective hydrogenation of the former using $\mathrm{Ni} /$ Raney [16] or Ru/C [17].

Moreover, dihydrochalcones are important intermediates for the synthesis of naturally derived artificial sweeteners like Neohesperidin dihydrochalcone and Naringin dihydrochalcone [18]. Dihydrochalcone moieties also show interesting pharmacological properties such as anti-oxidant [19], anti-inflammatory [20] and anti-leishmaniasis [21] activities. Selective hydrogenation of the chalcones' double bond to give dihydrochalcones is achieved using the metal/Lewis acid system $\mathrm{Zn} / \mathrm{HOAc}$ with ultrasound irradiation [22], with in situ generation of $\mathrm{H}_{2}$ using the system $\mathrm{Et}_{3} \mathrm{SiH} / \mathrm{Pd}-\mathrm{C}$ [23] or using $\mathrm{Pd} / \mathrm{C}$ together with a poisoning system $\mathrm{Ph}_{2} \mathrm{~S}$ to achieve high selectivities [24].

Another class of high synthetic relevance is represented by that of sulfones. These functional groups are found very commonly in drug molecules and fine chemicals. Despite the fact that the selective hydrogenation of $\alpha, \beta$-unsaturated sulfones represents a great synthetic challenge, very few examples of catalytic reactions can be found in the literature. The selective hydrogenation of the double 
bond can be achieved using binuclear palladium complexes [25] or using an ammonium formate/Pd-C system [26] or $\mathrm{Pd} / \mathrm{C}$ as in the synthesis of Eletriptan [27].

Some of us have already reported on the use of highly dispersed copper catalysts as very active and selective systems for the reduction of $\beta$-ionone and 4-(6-methoxy-2-naphtalenyl)-2-butanone [28]. The use of copper instead of $\mathrm{Ni}$ or noble metal systems would be highly desirable. In fact, for example, Ni/Raney is known to be pyrophoric, leading to several safety related issues. Moreover, nickel is suspected to be carcinogenic and skin-sensitizing according to the European Chemicals Agency (ECHA) [29]. Thus, in addition to the economic advantage, the permitted concentration of $\mathrm{Cu}$ elemental impurities in drugs, products and substances with respect to the cited nickel, rhodium and palladium is significantly greater, up to two orders of magnitude [30]. This aspect is far from negligible, considering that the catalyst residues coming from the synthetic process are considered to be one of the main and somehow unavoidable contamination sources [8].

Here, we wish to report some new results obtained in the hydrogenation of a series of $\alpha, \beta$-unsaturated ketones and esters, as well as in the selective reduction of an unsaturated sulfone, thus significantly extending the synthetic scope of the materials proposed.

\section{Results and Discussion}

All the catalysts were prepared with the chemisorption-hydrolysis $(\mathrm{CH})$ technique by using silicas with different surface areas and pore volumes and a copper loading of $8 \%$ by weight. In particular, three different commercial silicas were used, namely a pyrogenic one $\left(\mathrm{SiO}_{2} \mathrm{~A}\right)$ and two non-pyrogenic ones $\left(\mathrm{SiO}_{2} \mathrm{~B}\right.$ and $\left.\mathrm{SiO}_{2} \mathrm{C}\right)$ with areas, pore volumes, $-\mathrm{OH}$ surface density and surface contact angle values reported in Table 1.

Table 1. Textural properties of silicas used as supports.

\begin{tabular}{ccccc}
\hline Support & $\mathbf{S S A}\left(\mathbf{m}^{\mathbf{2}} \mathbf{g}^{\mathbf{1}}\right)$ & $\mathbf{P V}\left(\mathbf{m L ~ g}^{-\mathbf{1}}\right)$ & $\mathbf{m m o l}_{\mathbf{O H}} \mathbf{g}_{\mathbf{c a t}} \mathbf{- 1}$ & Contact Angle \\
\hline $\mathrm{SiO}_{2} \mathrm{~A}$ & 380 & - & 1.51 & $31^{\circ}$ \\
\hline $\mathrm{SiO}_{2} \mathrm{~B}$ & 460 & 0.74 & 3.8 & $19^{\circ}$ \\
\hline $\mathrm{SiO}_{2} \mathrm{C}$ & 693 & 0.62 & 4.1 & $17^{\circ}$ \\
\hline
\end{tabular}

The main results obtained with different kind of silica-supported copper catalysts in the hydrogenation of $\alpha, \beta$-unsaturated compounds, both ketones and esters, are presented in Table 2.

As already observed in the cases of $\beta$-ionone and Nabumetone [28], the $\mathrm{CH} \mathrm{Cu} / \mathrm{SiO}_{2}$ catalysts were revealed to be excellent systems for the selective hydrogenation of $\alpha, \beta$-unsaturated systems, showing very good performances also with other substrates of potential interest, such as pharmaceutical and F\&F intermediates and with unsaturated esters.

It is important to note that from the thermodynamic point of view $\mathrm{C}=\mathrm{C}$ bonds should be hydrogenated more easily than $\mathrm{C}=\mathrm{O}$ bonds. However, due to electronic delocalization in $\alpha, \beta$-unsaturated carbonyl compounds, $\mathrm{C}=\mathrm{O}$ bonds could be hydrogenated preferentially with respect to $\mathrm{C}=\mathrm{C}$ bonds [2].

$\mathrm{Cu} / \mathrm{SiO}_{2} \mathrm{~A}$ allows one to obtain a very high conversion and almost complete selectivity in the $\mathrm{C}=\mathrm{C}$ hydrogenation with all the substrates tested, and the same results can be obtained with $\mathrm{Cu} / \mathrm{SiO}_{2}$ $\mathrm{B}$, but with a slightly slower rate. An even more marked decrease in activity was observed when using $\mathrm{Cu} / \mathrm{SiO}_{2} \mathrm{C}$ (Entries 5 and 8). The lower selectivity observed in $\beta$-ionone hydrogenation (Entries 1 and 3 ) can be ascribed to the hydrogenation of $\mathrm{C}=\mathrm{O}$ to the alcohol giving the enol. By contrast, the general yield of the selective hydrogenation improves when the used substrate is an aromatic compound. This can be ascribed to a higher conjugation of the double bonds, leading to a minor activation energy required to hydrogenate the double bond [2]. 
Table 2. Selective reduction of different $\alpha, \beta$-unsaturated compounds with silica-supported copper catalysts at $90^{\circ} \mathrm{C}$ and 1 Bar of $\mathrm{H}_{2}$.

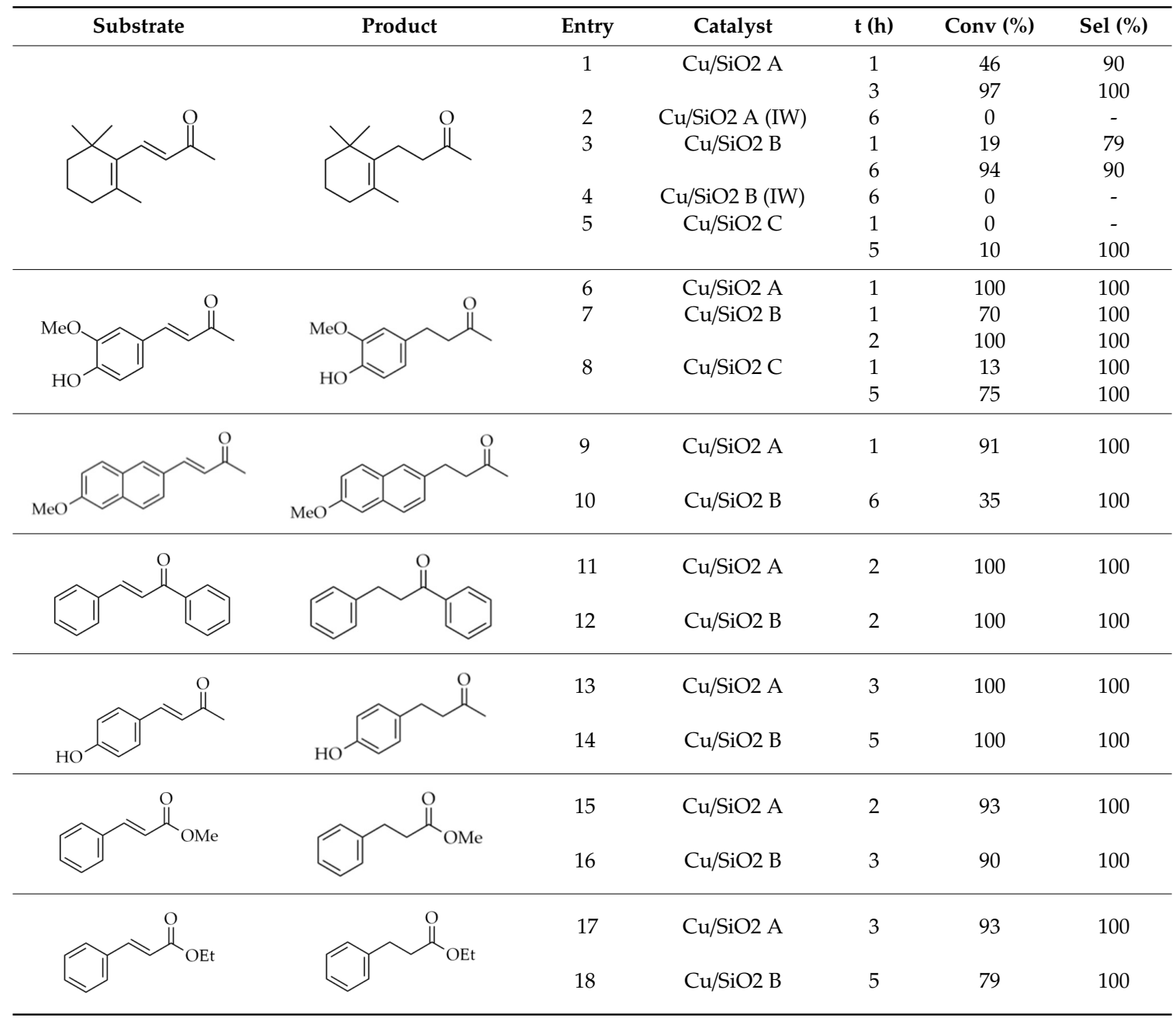

The $\mathrm{CH}$ preparation method is based on the electrostatic interaction established between the precursor solution and the support surface, and it was used in the present study for each of the silicas chosen as the supports [31]. The catalyst is prepared by dispersing the silica support in a basic $\left[\mathrm{Cu}\left(\mathrm{NH}_{3}\right)_{4}\right]^{2+}$ solution $(\mathrm{pH}=9)$, well above the silica zero point charge. This means that, under these conditions, the silica surface will be negatively charged, driving a preferential adsorption of $\mathrm{Cu}^{2+}$ cationic species on silica. The procedure grants a very high dispersion of the copper oxide phase, ten times higher with respect to catalysts prepared with the same copper loading using the traditional incipient wetness (IW) technique [31] and the formation of very well-formed metal particles upon the following reduction [32].

Both of these aspects reflect into a very high activity of this class of catalytic systems in a wide variety of hydrogenation reactions, ranging from $\mathrm{C}=\mathrm{C}$ double bond [33] to carbonyl compounds [34], although copper supported materials are not usually counted among the catalysts of choice in hydrogenation reactions, as $\mathrm{Pd}, \mathrm{Rh}, \mathrm{Pt}, \mathrm{Ni}$ and $\mathrm{Ru}$ are the most employed ones [35].

The pivotal role of the preparation method is also confirmed in the present application, as shown by the complete inactivity of the catalysts prepared with the traditional IW technique (Entries 2 and 4, Table 2).

Scanning transmission electron microscopy (STEM) analysis confirmed the presence of small (mean size diameter $2.4 \mathrm{~nm}$ ) well-shaped and highly dispersed $\mathrm{Cu}$ nanoparticles (Figure 1). STEM 
images allowed us to highlight the nanoparticles, which are brighter in the images, and distinguish them from the amorphous $\mathrm{SiO}_{2}$ support.
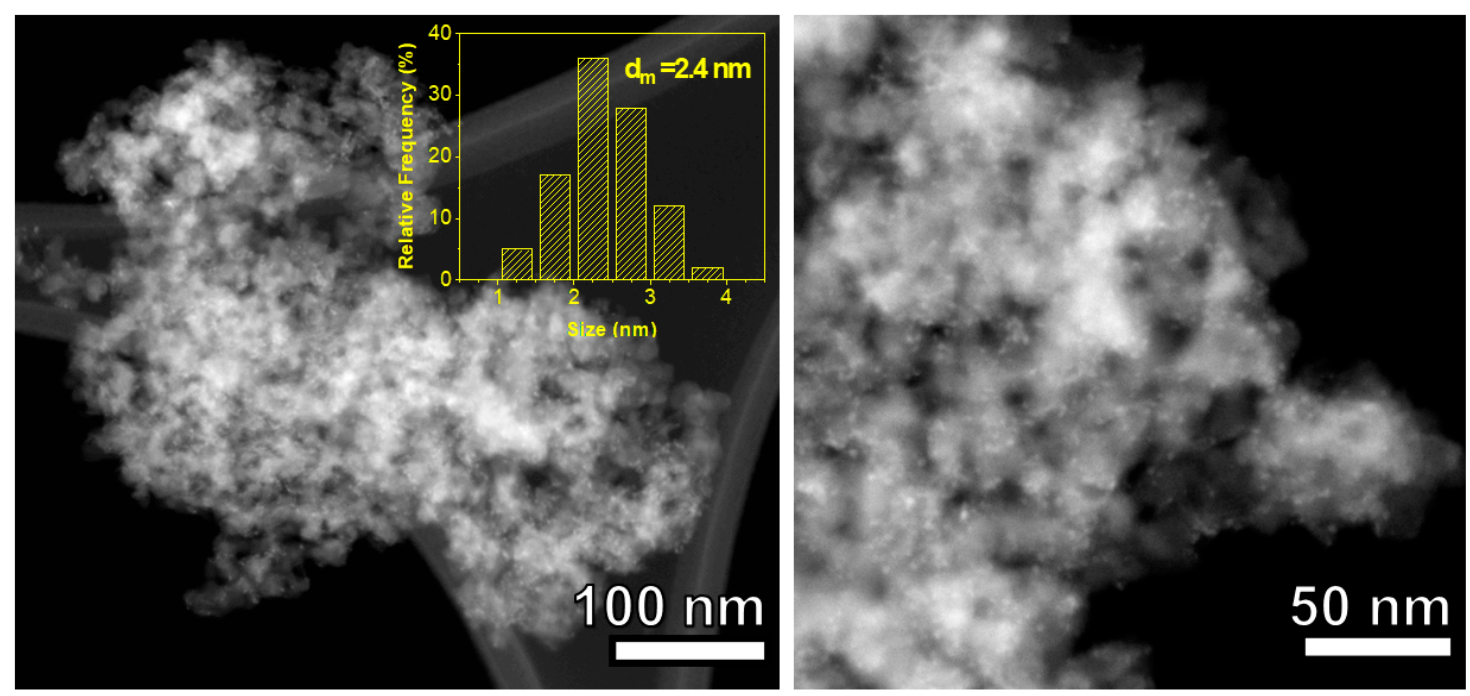

Figure 1. Representative STEM images of sample $\mathrm{Cu} / \mathrm{SiO}_{2} \mathrm{~A}$ and related particle size distribution (inset on the left side).

The preparation method, and in turn the very high dispersion obtained, also reflect on the acidic properties of the copper catalysts presented here.

The role of Lewis acid sites in promoting both activity and selectivity in the hydrogenation of $\alpha, \beta$-unsaturated carbonyl compounds is well known. Thus, they can coordinate with the Lewis basic $\mathrm{C}=\mathrm{O}$ group via one of the oxygen lone pairs, thereby affecting the electronic distribution of the $\mathrm{C}=\mathrm{C}$ bond and in turn its aptitude (proneness) to hydrogenation (Figure 2). Some catalytic systems have taken advantage of the synergy between metals with high hydrogenation activity and Lewis acid to reach excellent yield in the desired product. Pt nanoparticles deposited on an acidic MIL-101 MOF allowed us to achieve quantitative transformation of cinnamaldehyde into dihydro-cinnamaldehyde at room temperature and under atmospheric pressure of $\mathrm{H}_{2}$ [36] while $\mathrm{Pd}$ nanocubes assembled with an Fe-containing MIL101 MOF gave an improved selectivity and a 20-fold increased TOF (Turnover Frequency) with respect to the nude Pd catalyst in the hydrogenation of $\beta$-ionone [37]. In the case of $\mathrm{Cu} / \mathrm{SiO}_{2}$ catalysts, some of us already showed that the very small and well-structured $\mathrm{CuO}$ and $\mathrm{Cu}$ particle-exposing step and edges can act as Lewis acid sites promoting reactions such as the opening of epoxides [38] or nucleophilic addition to the carbonyl group [32].

The important effect in terms of metallic phase dispersion is granted by the peculiar preparation method. On the other hand, the effect of the oxide or mixed oxide chosen as the support can play an important role in driving the selectivity of the reaction by exploiting different acid base properties or textural features $[39,40]$.

In the present case, the differences observed within the three different commercial silicas used as supports mainly rely on the activity. The main textural and surface properties of the silicas used are reported in Table 1, and some considerations can be made with respect to the density of hydroxyl groups over the surface. Silica gels such as B and C present a higher hydrophilicity compared to pyrogenic silicas such as silica A. 


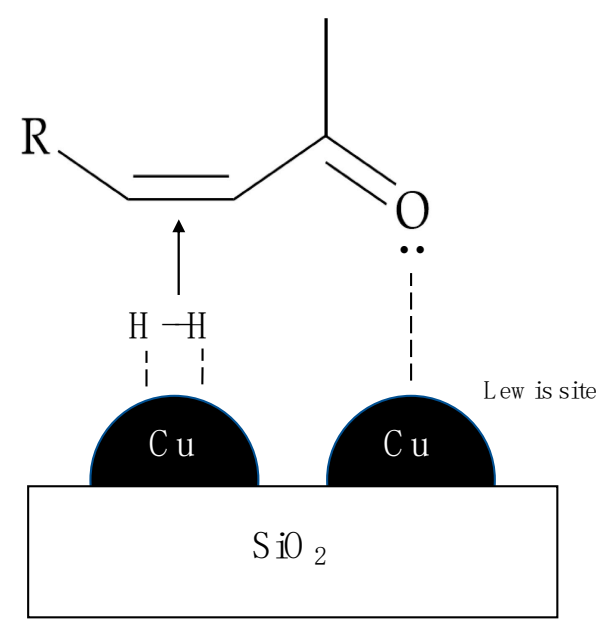

Figure 2. Lewis site role in the double bond hydrogenation of an $\alpha, \beta$-unsaturated carbonyl compound.

Figure 3 shows the values of productivity (expressed as $\mathrm{mmol}_{\text {prod }} \mathrm{g}_{\text {cat }}{ }^{-1} \mathrm{~h}$ ) obtained with $\mathrm{Cu} / \mathrm{SiO}_{2}$ A, $\mathrm{Cu} / \mathrm{SiO}_{2} \mathrm{~B}$ and $\mathrm{Cu} / \mathrm{SiO}_{2} \mathrm{C}$ in the hydrogenation of $\beta$-ionone and the precursor of vanillylacetone (zingerone) versus the hydrophilicity of the silicas used as the supports, expressed as $\mathrm{mmol}_{\mathrm{OH}} \mathrm{g}^{-1}$. In terms of productivity, the best results were achieved with $\mathrm{Cu} / \mathrm{SiO}_{2} \mathrm{~A}$, which allowed us to obtain a value of $12.2 \mathrm{mmol}_{\text {prod }} \mathrm{g}_{\mathrm{cat}}{ }^{-1} \mathrm{~h}$ in the case of vanillylacetone.

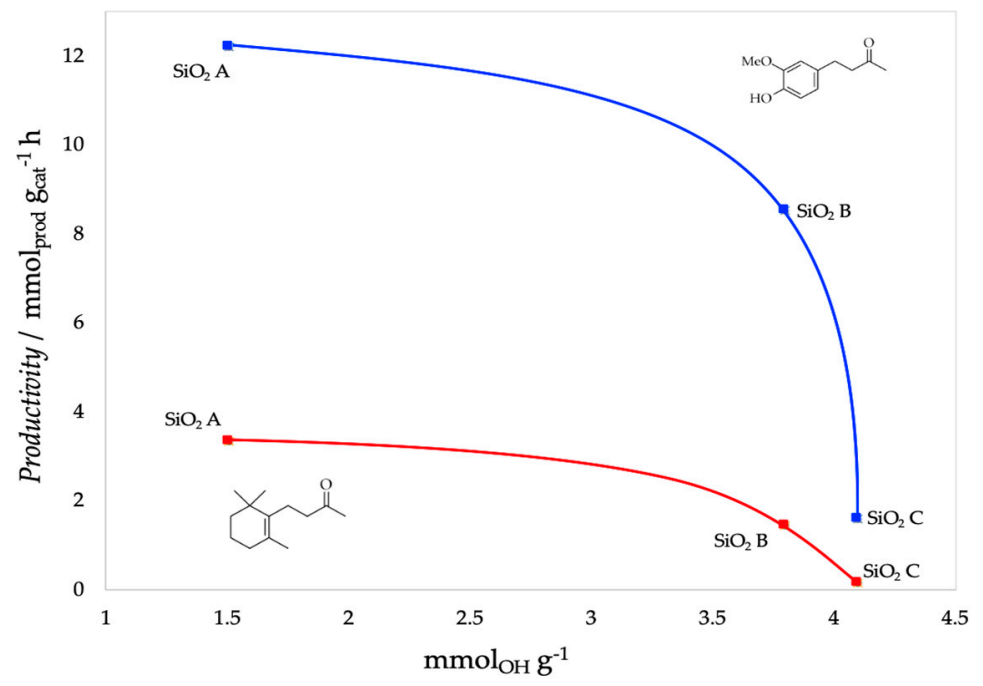

Figure 3. Productivity vs. hydroxyl group density of different silica catalysts in the hydrogenation of $\beta$-ionone and vanyllilacetone.

The hydrophilic/hydrophobic properties of the support have been recently shown by some of us to have a significant role in the hydrogenation of carbonyl compounds to alcohols or diols [41]. This is due to interactions taking place between the hydroxyl groups of the product and the support surface, promoting desorption of the alcohol/diol when this is more hydrophobic.

From data reported in the graph, a common trend can be observed for both substrates, showing a correlation between the two values: the lower the hydrophilicity of the support, the higher the activity. This evidence is in agreement with the easier interaction of the $C=C$ bond with a less polar surface.

This aspect has also been investigated by measuring the surface contact angle for the three silicas using propandiol drops instead of conventional water in order to elucidate the differences among silicas. As shown in Figure 4, the higher the contact angle, the higher the productivity obtained, confirming the trend observed with TGA measurements reported in Figure 3. Thus, the contact angle 
value increases with hydrophobicity, while the $-\mathrm{OH}$ density decreases. Data reported in Figures 3 and 4 are therefore consistent in showing that productivity improves when using a more hydrophobic silica as the catalyst support. The more pronounced differences observed in the case of vanyllilacetone bearing an $-\mathrm{OH}$ group could be ascribed to the easier desorption of the product from the surface, thus speeding up the reaction, or generally to the presence of the aromatic group that is known to establish interactions with silanol groups via hydrogen bonding [42]. All these aspects could contribute to competition phenomena.

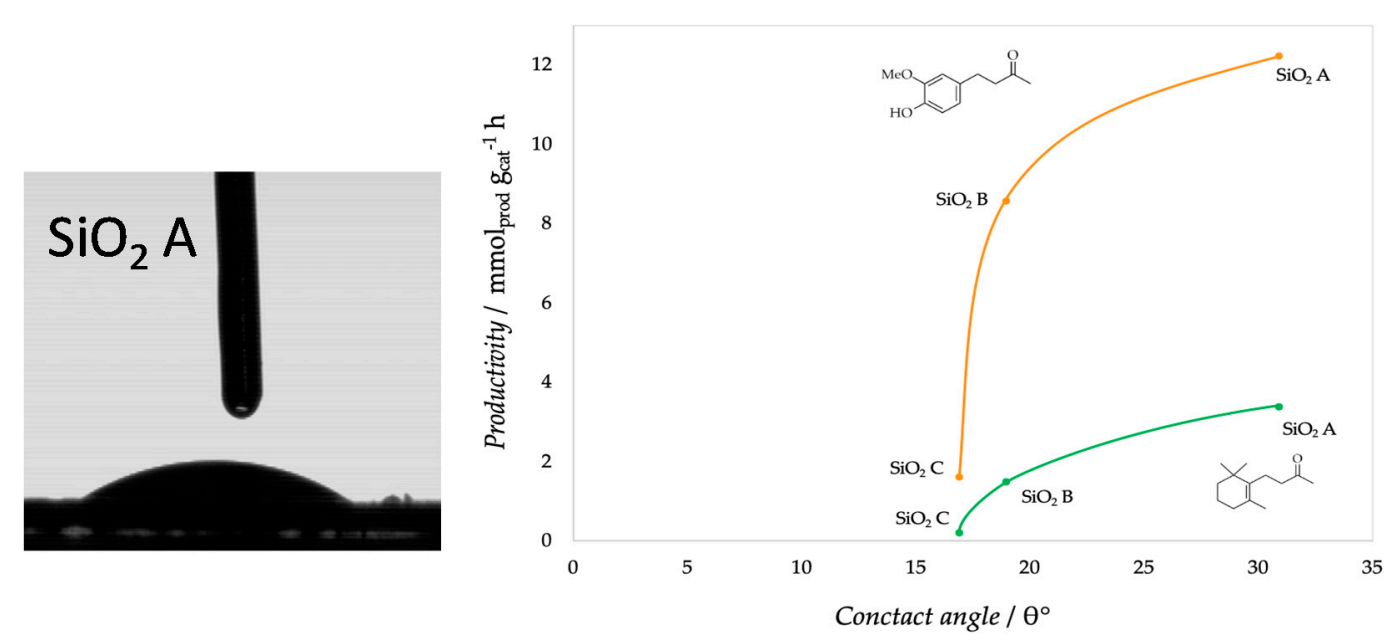

Figure 4. Productivity vs. surface contact angle of different silica catalysts in the hydrogenation of $\beta$-ionone and vanyllilacetone and picture of the contact angle measurement.

As clearly shown in Figure 5, the hydrogenation of the carbonyl group is also possible under the conditions used. However, the reaction proceeds in two well-separated steps, thus allowing the easy recovery of the pure desired product. An induction period of $1 \mathrm{~h}$ can be observed between the two hydrogenation steps. An explanation to this phenomenon could be found in the amount of time needed by the keto-enolic tautomerism to shift towards the enolic form.

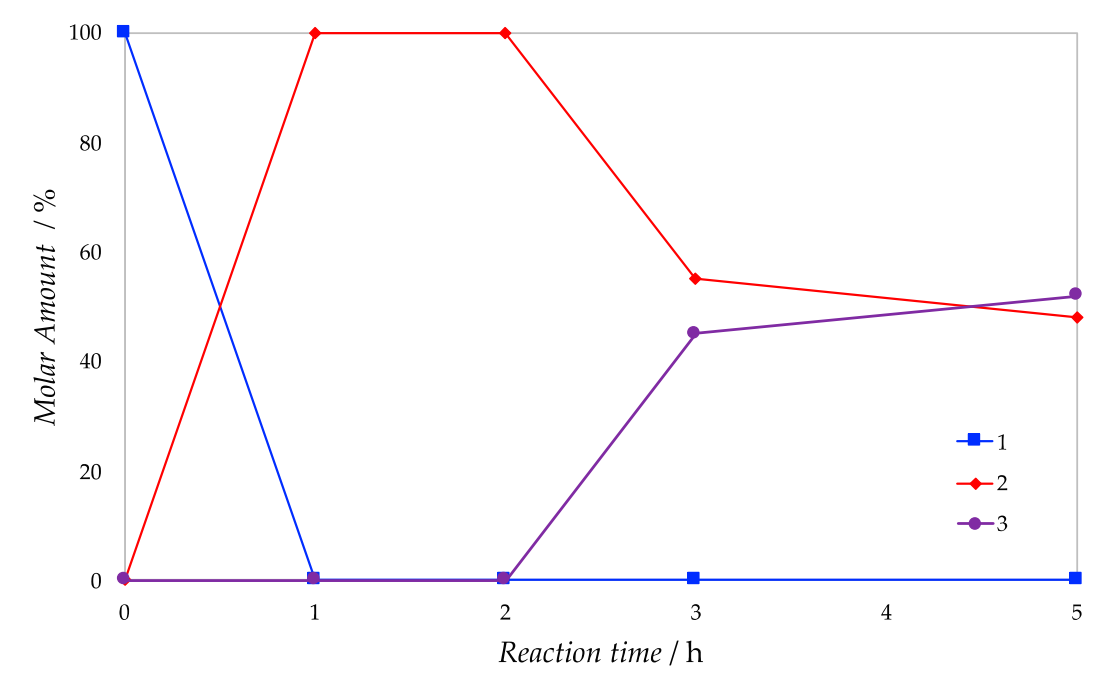

Figure 5. Molar percentages of reagent and products vs. time of zingerone hydrogenation reaction. 
<smiles>COc1cc(/C=C/C(C)=O)ccc1O</smiles>

1<smiles>COc1cc(CCC(C)=O)ccc1O</smiles>

2<smiles>COc1cc(CCC(C)O)ccc1O</smiles>

3

Moreover, $\mathrm{Cu} / \mathrm{SiO}_{2}$ A catalyst can be recycled without being pretreated four times, observing only a slight decrease in conversion while keeping selectivity unchanged in all the tests performed (Figure 6). The catalysts were simply separated from the reaction mixture and dried under nitrogen without any pre-treatment before each recycle step. This could justify the slight decrease in the activity of the catalyst, probably due to a pale poisoning and partial deactivation of the active sites. On the other hand, ICP (Inductively Coupled Plasma) analysis does not show any copper leaching taking place after the hydrogenation reaction, thus allowing us to exclude the effect of a lower copper content in the system.

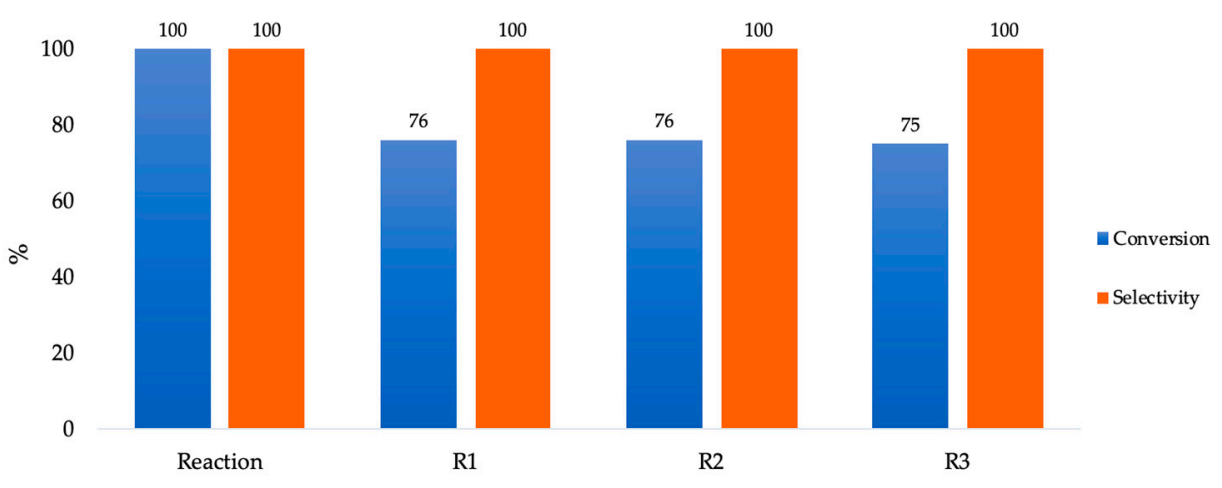

Figure 6. Recycles of hydrogenation of 4-(4-Hydroxyphenyl)but-3-en-2-one with $\mathrm{Cu} / \mathrm{SiO}_{2} \mathrm{~A}$.

The high activity observed for $\alpha, \beta$-unsaturated compounds by using copper catalysts prompted us to investigate their application to another class of substrates of interest, namely unsaturated sulfones. As already mentioned in the introduction, the molecules in this class are precursors of some important pharma products such as Eletriptan, a drug for the treatment of migraine headaches [27]. In this case, aside from the already mentioned toxicity problems, the use of noble metal-based catalysts entails other selectivity concerns, such as the formation of products derived from $\mathrm{C}-\mathrm{S}$ hydrogenolysis side reaction. $\mathrm{Cu} / \mathrm{SiO}_{2} \mathrm{~A}$ and $\mathrm{Cu} / \mathrm{SiO}_{2} \mathrm{~B}$, which were the highest-performing catalysts in the $\alpha, \beta$-unsaturated compounds, were therefore tested in the hydrogenation of sulfone 4 into the corresponding saturated 5 .

A very similar trend was observed in the chemoselective reduction of $\alpha, \beta$-unsaturated sulfone 4. Furthermore, in the reduction of the $\mathrm{C}=\mathrm{C}$ double bond conjugated with $\mathrm{SO}_{2}$ group, both of the silica-supported catalysts showed a good activity and a very high selectivity into the saturated sulfone 5 , thus showing, to the best of our knowledge, an unprecedented use of heterogeneous copper systems for this application. Moreover, also in this case, the catalyst supported on the less hydrophilic silica A gave a better performance.

For these substrates, the main undesired reaction is the hydrogenolysis into styrene and ethylbenzene, which is limited to less than $1 \%$ (Table 3). Thus, with $\mathrm{Cu} / \mathrm{SiO}_{2} \mathrm{~A}$, it is possible to obtain a $>99 \%$ conversion with $98 \%$ of 5 within $6 \mathrm{~h}$ at $90{ }^{\circ} \mathrm{C}$ and 1 Bar of hydrogen. Interestingly, these catalysts are also active on sulfur compounds. This was also observed in the synthesis of thioethers starting from benzyl mercaptans and phenols. 
Table 3. Trans-phenyl-styrylsulfone hydrogenation reactions with silica-supported Cu catalysts at 1 Bar of $\mathrm{H}_{2}$.

\begin{tabular}{|c|c|c|c|c|}
\hline Catalyst & $\mathrm{T}\left({ }^{\circ} \mathrm{C}\right)$ & $t(h)$ & Conv (\%) & Sel $5(\%)$ \\
\hline \multirow{5}{*}{$\mathrm{Cu} / \mathrm{SiO}_{2} \mathrm{~B}$} & \multirow{5}{*}{90} & 1 & 35 & 98 \\
\hline & & 2 & 55 & 98 \\
\hline & & 4 & 78 & 98 \\
\hline & & 7 & 98 & 99 \\
\hline & & 24 & $>99$ & 98 \\
\hline \multirow{3}{*}{$\mathrm{Cu} / \mathrm{SiO}_{2} \mathrm{~A}$} & \multirow{3}{*}{90} & 1 & 66 & 98 \\
\hline & & 2 & 94 & 98 \\
\hline & & 4 & $>99$ & 98 \\
\hline \multirow{3}{*}{$\mathrm{Cu} / \mathrm{SiO}_{2} \mathrm{~A}$} & \multirow{3}{*}{70} & 2 & 19 & 99 \\
\hline & & 4 & 31 & 99 \\
\hline & & 24 & 92 & 98 \\
\hline
\end{tabular}

The chance of using a low toxicity metal such as $\mathrm{Cu}$ in the final step of the synthesis of this kind of molecule is even more relevant if we consider that the maximum permitted daily exposure (PDE) in oral administration in a pharma product is $3400 \mu \mathrm{g}$ day $^{-1}$ for $\mathrm{Cu}$, compared with $220 \mu \mathrm{g} \mathrm{day}^{-1}$ for Ni and $100 \mu$ day $^{-1}$ for a Pt group metal.<smiles>O=S(=O)(/C=C/c1ccccc1)c1ccccc1</smiles>

\section{Materials and Methods}

\subsection{Materials}

Copper catalysts with a metal loading of $8 \%$ by weight of metal to weight of support were prepared with an already reported method called chemisorption-hydrolysis [31]. The right amount of $\mathrm{Cu}\left(\mathrm{NO}_{3}\right)_{2}$ was dissolved in $20 \mathrm{~mL}$ of distilled water and the $\mathrm{pH}$ of the solution was brought to 9 with an $\mathrm{NH}_{4} \mathrm{OH}$ solution. The corresponding support was added, and the obtained slurry was diluted with $3 \mathrm{~L}$ of distilled water at $0^{\circ} \mathrm{C}$. The supports used were $\mathrm{SiO}_{2} \mathrm{~A}\left(\mathrm{SSA}=380 \mathrm{~m}^{2} \mathrm{~g}^{-1}\right)$ from Evonik, $\mathrm{SiO}_{2}$ $\mathrm{B}\left(\mathrm{BET}=460 \mathrm{~m}^{2} \mathrm{~g}^{-1} \mathrm{PV}=0.74 \mathrm{~mL} \mathrm{~g}^{-1}\right)$ purchased from Sigma-Aldrich (Merck) and $\mathrm{SiO}_{2} \mathrm{C}(\mathrm{SSA}=$ $693 \mathrm{~m}^{2} \mathrm{~g}^{-1} ; \mathrm{PV}=0.62 \mathrm{~mL} \mathrm{~g}^{-1}$ ) purchased from Mitsubishi Chemical Corporation. The obtained solid was then filtered and dried overnight at $110^{\circ} \mathrm{C}$. It was then calcined at $350{ }^{\circ} \mathrm{C}$ for $4 \mathrm{~h}$ in air. Before any reaction, the catalysts were pretreated at $270{ }^{\circ} \mathrm{C}$ under vacuum and reduced in a hydrogen atmosphere at the same temperature.

The incipient wetness (IW) sample was prepared by impregnating the silica support with a copper nitrate solution of proper concentration and volume in order to obtain $8 \% \mathrm{wt} / \mathrm{wt}$ loaded catalyst over the same silica as the support.

\subsection{TGA Analysis}

Thermogravimetric analysis (TGA) was conducted on a PerkinElmer (Italy) 7 HT thermobalance. The analysis was performed by heating the samples from 50 to $1000{ }^{\circ} \mathrm{C}$ with a temperature ramp of $5{ }^{\circ} \mathrm{C} \mathrm{min}-1$. Loss of water was evaluated in the temperature range between 250 and $900{ }^{\circ} \mathrm{C}$, and $\mathrm{mmol}_{\mathrm{OH}}$ per $\mathrm{g}_{\mathrm{cat}}$ was calculated using this formula: $[(2 \times \Delta \mathrm{wt} \%) \times 10] / 18\left(\mathrm{~g} \mathrm{~mol}^{-1}\right)$. 


\subsection{TEM Analysis}

Scanning transmission electron microscopy (STEM) analysis was performed using a ZEISS LIBRA200FE. The sample was gently smashed in an agate mortar, suspended in isopropyl alcohol for $20 \mathrm{~min}$ in an ultrasonic bath and dropped onto a lacey carbon-coated copper TEM grid. The sample was analyzed after complete solvent evaporation.

\subsection{Conctact Angle Measurements}

Static contact angle measurements of solid supports were performed with a Krüss Easy instrument on a disk of the sample (solid supports). A 1,3-propanediol drop of $5 \mu \mathrm{L}$ was produced and gently placed on the surface. The drop profile was extrapolated using an appropriate fitting function. Measurements were repeated several times to obtain a statistically relevant population.

\subsection{Hydrogenation Reactions}

A $9 \mathrm{~mL}$ solution of the reagent $(0.5 \mathrm{mmol})$ in toluene was added under a nitrogen atmosphere to a reaction vessel containing the pre-reduced catalyst $(50 \mathrm{mg}, 0.06 \mathrm{~mol}$ of $\mathrm{Cu}$ ). The reactions were carried out at different temperature under a hydrogen atmosphere and using magnetic stirring. The reaction was monitored through gas chromatography-mass spectrometry (GC-MS) (Agilent 5957C) by using a HP-5 column ( $5 \%$ phenylmethylpolysiloxane). The conversion and the selectivity of each reaction were determined with the same method. The recycling was carried out by simply decanting the suspension, removing the reaction solution and adding the fresh one to the system. In the case of hydrogenation of trans-phenyl- $\alpha, \beta$-styrylsulfone, an $8 \mathrm{~mL}$ solution of the reagent $(0.5 \mathrm{mmol})$ in $n$-heptane were added under nitrogen atmosphere in a reaction vessel containing the pre-reduced catalyst $(100 \mathrm{mg})$.

\section{Conclusions}

The use of highly dispersed copper catalysts onto silica prepared with an electrostatic interaction strategy allows one to selectively reduce $C=C$ double bonds in a wide range of $\alpha, \beta$-unsaturated systems. Both the preparation method and the silica used as the support contribute to the high activity observed. In particular, hydrophobicity of the silica used was revealed to be an important aspect in the activity observed. The use of copper catalysts instead of the usually proposed noble metal- or Ni-based systems represents a great advantage as far as toxicity issues are concerned when designing a hydrogenation step for pharma or F\&F products.

Author Contributions: Conceptualization, N.R., F.Z. and O.P.; methodology, D.C.; formal analysis, D.C. and M.M.; investigation, D.C., F.Z. and C.E.; data curation, F.Z. and N.R; writing—original draft preparation, D.C and F.Z.; writing-review and editing, N.R. All authors have read and agreed to the published version of the manuscript.

Funding: This research received no external funding

Conflicts of Interest: The authors declare no conflict of interest.

\section{References}

1. Patai, S.; Rappoport, Z. The Chemistry of Enones; John Wiley \& Sons Ltd.: Chichester, UK, 1986.

2. Rinaldi, R. Catalytic Hydrogenation for Biomass Valorization; RSC: Cambridge, UK, 2014.

3. Fitch, J.R.; Aslam, M.; Rios, D.E.; Smith, J.C. Use of 4-Substituted 2-Butanones to Prepare Nabumetone. Patent EP0892775A2, 27 January 1997.

4. Mody, P.A.; Motivala, J.K.; Mehta, C.D. A Novel Process for the Manufacture of 4-(6-Methoxy-2-naphthyl) buten-2-one and Its Pharmaceutical Composition, from a Novel Source. Indian Patent 178589, 1997.

5. Ramachandran, V.; Belmont, S. Production of Naphthyl-Substituted Ketones from Naphthaldehydes. Patent US5861538A, 8 December 1998.

6. Cabri, W.; Magrone, D.; Oldani, E.; Angelici, R. U.S. Process for the Preparation of 4-(6'-methoxy-2'-naphthyl) Butan-2-One. U.S. Patent 5955635, 21 September 1999. 
7. Piccolo, O.; Verrazzani, A. Preparation and Use of a Heterogeneous Rhodium Catalyst for the Hydrogenation of a Double Bond of an $\alpha-\beta$-Unsaturated Carbonyl Compound. U.S. Patent US7087548B2, 8 August 2006.

8. Viviano, M.; Glasnov, T.N.; Reichart, B.; Tekautz, G.; Kappe, C.O. A scalable two-step continuous flow synthesis of nabumetone and related 4-aryl-2-butanones. Org. Process Res. Dev. 2011, 15, 858-870. [CrossRef]

9. Evangelisti, C.; Panziera, N.; Vitulli, M.; Pertici, P.; Balzano, F.; Uccello-Barretta, G.; Salvadori, P. Supported rhodium nanoparticles obtained by Metal Vapour Synthesis as catalysts in the preparation of valuable organic compounds. Appl. Catal. A Gen. 2008, 339, 84-92. [CrossRef]

10. Bartoli, M.; Rosi, L.; Petrucci, G.; Armelao, L.; Oberhauser, W.; Frediani, M.; Piccolo, O.; Rathod, V.D.; Paganelli, S. An easily recoverable and recyclable homogeneous polyester-based Pd catalytic system for the hydrogenation of $\alpha, \beta$-unsaturated carbonyl compounds. Catal. Commun. 2015, 69, 228-233. [CrossRef]

11. Malkar, R.S.; Yadav, G.D. Selectivity Engineering in One Pot Synthesis of Raspberry Ketone: Crossed Aldol Condensation of p-Hydroxybenzaldehyde and Acetone and Hydrogenation over Novel Ni/Zn-La Mixed Oxide. ChemistrySelect 2019, 4, 2140-2152. [CrossRef]

12. Mehanna, E.T.; Barakat, B.M.; ElSayed, M.H.; Tawfik, M.K. An optimized dose of raspberry ketones controls hyperlipidemia and insulin resistance in male obese rats: Effect on adipose tissue expression of adipocytokines and Aquaporin 7. Eur. J. Pharmacol. 2018, 832, 81-89. [CrossRef] [PubMed]

13. Chen, J.C.; Huang, L.J.; Wu, S.L.; Kuo, S.C.; Ho, T.Y.; Hsiang, C.Y. Ginger and its bioactive component inhibit enterotoxigenic Escherichia coli heat-labile enterotoxin-induced diarrhea in mice. J. Agric. Food Chem. 2007, 55, 8390-8397. [CrossRef]

14. Bandarenko, M.; Kovalenko, V. Synthesis of raspberry and ginger ketones by nickel boride-catalyzed hydrogenation of 4-arylbut-3-en-2-ones. Zeitschrift fur Naturforsch. Sect. B J. Chem. Sci. 2014, 69, 885-888. [CrossRef]

15. Smith, L.R. Rheosmin (Raspberry Ketone) and Zingerone, and Their Preparation by Crossed Aldol-Catalytic Hydrogenation Sequences. Chem. Educ. 1996, 1, 1-18. [CrossRef]

16. Masuda, H.; Mihara, S. Production of Dihydro- $\beta$-ionol. Japanese Patent 61,036239, 1986.

17. Chapuis, C.; Jacoby, D. Catalysis in the preparation of fragrances and flavours. Appl. Catal. A General 2001, 221, 93. [CrossRef]

18. Kinghorn, A.D.; Chin, Y.W.; Pan, L.; Jia, Z. Natural products as sweeteners and sweetness modifiers. Compr. Nat. Prod. II Chem. Biol. 2010, 3, 269-315.

19. Nakamura, Y.; Watanabe, S.; Miyake, N.; Kohno, H.; Osawa, T. Dihydrochalcones: Evaluation as novel radical scavenging antioxidants. J. Agric. Food Chem. 2003, 51, 3309-3312. [CrossRef] [PubMed]

20. Zhao, F.; Nozawa, H.; Daikonnya, A.; Kondo, K.; Kitanaka, S. Inhibitors of nitric oxide production from hops (Humulus lupulus L.). Biol. Pharm. Bull. 2003, 26, 61-65. [CrossRef] [PubMed]

21. Hermoso, A.; Jiménez, I.A.; Mamani, Z.A.; Bazzocchi, I.L.; Piñero, J.E.; Ravelo, A.G.; Valladares, B. Antileishmanial activities of dihydrochalcones from piper elongatum and synthetic related compounds. Structural requirements for activity. Bioorg. Med. Chem. 2003, 11, 3975-3980. [CrossRef]

22. Zhang, L.; Zhang, W.; Wang, X.; Bao, K.; Lu, G.; Lin, J. Ultrasound Assisted Selective Reduction of Chalcones to Dihydrochalcones by Zn/HOAc. Lett. Org. Chem. 2008, 5, 370-373. [CrossRef]

23. Jesus, A.R.; Marques, A.P.; Rauter, A.P. An easy approach to dihydrochalcones via chalcone in situ hydrogenation. Pure Appl. Chem. 2016, 88, 349-361. [CrossRef]

24. Mori, A.; Mizusaki, T.; Miyakawa, Y.; Ohashi, E.; Haga, T.; Maegawa, T.; Monguchi, Y.; Sajiki, H. Chemoselective hydrogenation method catalyzed by $\mathrm{Pd} / \mathrm{C}$ using diphenylsulfide as a reasonable catalyst poison. Tetrahedron 2006, 62, 11925-11932. [CrossRef]

25. Cho, I.S.; Alper, H. Palladium Catalyzed Hydrogenation of $\alpha, \beta$-Unsaturated Sulfones and Phosphonates. J. Org. Chem. 1994, 59, 4027-4028. [CrossRef]

26. Ranu, B.C.; Guchhait, S.K.; Ghosh, K. Chemoselective Hydrogenation of $\alpha, \beta$-Unsaturated Sulfones and Phosphonates via Palladium-Assisted Hydrogen Transfer by Ammonium Formate. J. Org. Chem. 1998, 63, 5250-5251. [CrossRef]

27. Serafini, S.; Castellin, A.; Dal Santo, C. Synthesis of 3-\{[(2R)-1-methylpyrrolidin-2-yl]methyl\}-5[2(phenylsulfonyl)ethyl]-1H-Indole. U.S. Patent US8426612B2, 23 April 2013.

28. Ravasio, N.; Zaccheria, F.; Allegrini, P.; Ercoli, M. Selective hydrogenation of 4-(6-methoxy-2-naphtyl)3-buten-2-one to Nabumetone ${ }^{\circledR}$. Catal. Today 2007, 121, 2-5. [CrossRef]

29. Available online: https://echa.europa.eu/ (accessed on 6 May 2020). 
30. Agency, E.M. ICH Guideline Q3D on Elemental Impurities. 2016, 44, p. 84. Available online: www.ema. europa.eu/contact (accessed on 6 May 2020).

31. Zaccheria, F.; Scotti, N.; Marelli, M.; Psaro, R.; Ravasio, N. Unravelling the properties of supported copper oxide: Can the particle size induce acidic behaviour? Dalt. Trans. 2013, 42, 1319-1328. [CrossRef]

32. Scotti, N.; Dangate, M.; Gervasini, A.; Evangelisti, C.; Ravasio, N.; Zaccheria, F. Unraveling the role of low coordination sites in a cu metal nanoparticle: A step toward the selective synthesis of second generation biofuels. ACS Catal. 2014, 4, 2818-2826. [CrossRef]

33. Zaccheria, F.; Psaro, R.; Ravasio, N. Selective hydrogenation of alternative oils: A useful tool for the production of biofuels. Green Chem. 2009, 11, 462-465. [CrossRef]

34. Zaccheria, F.; Ravasio, N.; Psaro, R.; Fusi, A. Heterogeneous selective catalytic hydrogenation of aryl ketones to alcohols without additives. Tetrahedron Lett. 2005, 46, 3695-3697. [CrossRef]

35. Augustine, R.L. Heterogeneous Catalysis for Synthetic Chemist; Marcel Dekker: New York, NY, USA, 1996; ISBN 0824790219.

36. Liu, H.; Li, Z.; Li, Y. Chemoselective hydrogenation of cinnamaldehyde over a Pt-Lewis acid collaborative catalyst under ambient conditions. Ind. Eng. Chem. Res. 2015, 54, 1487-1497. [CrossRef]

37. Bakuru, V.R.; Kalidindi, S.B. Synergistic Hydrogenation over Palladium through the Assembly of MIL-101(Fe) MOF over Palladium Nanocubes. Chem. A Eur. J. 2017, 23, 16456-16459. [CrossRef]

38. Zaccheria, F.; Santoro, F.; Psaro, R.; Ravasio, N. Heterogeneous: Copper catalysts for synthetic purposes Building new simple bifunctional materials. Chim. Oggi 2011, 29, $22-25$.

39. Zaccheria, F.; Ravasio, N.; Fusi, A.; Rodondi, M.; Psaro, R. Tuning selectivity in terpene chemistry: Selective hydrogenation versus cascade reactions over copper catalysts. Adv. Synth. Catal. 2005, 34, 1267-1272. [CrossRef]

40. Santoro, F.; Psaro, R.; Ravasio, N.; Zaccheria, F. Reductive Amination of Ketones or Amination of Alcohols over Heterogeneous $\mathrm{Cu}$ Catalysts: Matching the Catalyst Support with the N-Alkylating Agent. ChemCatChem 2012, 4, 1249-1254. [CrossRef]

41. Cavuoto, D.; Ravasio, N.; Scotti, N.; Cappelletti, G.; Venezia, A.M.; Zaccheria, F. The role of support wettability in the hydrogenation of $\gamma$-valerolactone over $\mathrm{Cu} / \mathrm{SiO} 2$. Catal. Today 2020, in prep.

42. Ringwald, S.C.; Pemberton, J.E. Adsorption interactions of aromatics and heteroaromatics with hydrated and dehydrated silica surfaces by raman and FTIR spectroscopies. Environ. Sci. Technol. 2000, 34, 259-265. [CrossRef]

(C) 2020 by the authors. Licensee MDPI, Basel, Switzerland. This article is an open access article distributed under the terms and conditions of the Creative Commons Attribution (CC BY) license (http://creativecommons.org/licenses/by/4.0/). 